\title{
Surgical Removal of a Focal Fibrous Hyperplasia: Two Case Reports
}

\author{
Zemmouri Yousra *, Chbicheb Saliha \\ Department of Oral Surgery-Consultation Center of Dental Treatment (CCTD),Faculty of Dentistry, University \\ Mohamed V Suissi, Rabat, Morocco
}

*Corresponding Author: ZEMMOURI Yousra; yousra.zemmouri@um5s.net.ma

Received 04 February 2021;

Accepted 16 February 2021;

Published 01 March 2021

\begin{abstract}
Focal fibrous hyperplasia is the most common epithelial benign tumor of the oral cavity. It is a localized reactive progressive, proliferation of oral mucosa in response to injury or local irritation. Females are twice more likely to develop fibroma than male.

Surgical excision is performed and histological examination of the excised specimen and definitive diagnosis was obtained. This paper reports two cases of focal fibrous hyperplasia in both maxillary and mandibular locations.
\end{abstract}

Keywords: irritation fibroma, benign tumor, Focal fibrous hyperplasia

\section{Introduction}

Focal fibrous hyperplasia is a localized reactive progressive, proliferation of oral mucosa in response to injury or local irritation ${ }^{[1]}$. The term "focal fibrous hyperplasia" implies a reactive tissue response and is therefore preferable to the term "fibroma" which implies incorrectly, a benign neoplastic proliferation of fibrous connective tissue ${ }^{[2,3]}$. The most common intraoral site is along the occlusal line of the buccal mucosa - an area subject to masticatory trauma - but it also affects the lower lip, tongue, hard palate and edentulous alveolar ridge. The occurrence of irritation fibromas among the Moroccan population was found to be $30.5 \%{ }^{[4]}$.

The histologic criteria of a true fibroma were first described by Barker and Lucas. Many more cases of true gingival fibroma have been reported in literature since then ${ }^{[1]}$.

The aim of our paper is to report two cases of focal fibrous hyperplasia located in both the maxillary and mandibular gingival mucosa.

\section{Case Report 1}

A 40-year-old female patient reported to the Oral Surgery Department of the Consultation Center of Dental Treatment with The chief complaint of bleeding from gums in maxillary posterior premolar region from past 6-7 months. No relevant medical history was reported. The lesion was gradually increased in size with history of bleeding and no pain.

The Intra-oral examination revealed a sessile firm in consistency and well defined growth mass in relation to 14,15 and
16 on the buccal side, measuring approximately $2 \times 2 \mathrm{~cm}$ in diameter, extending from mesial surface of 14 to mesial surface of 16 (Figure 1).

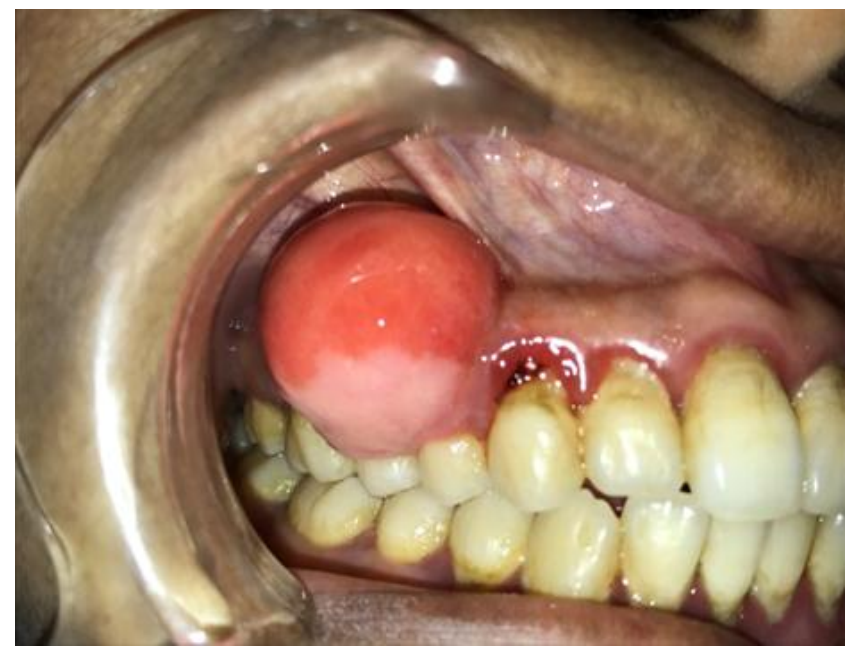

Fig. 1 Pre-operative View: Sessil mass located in the buccal gum mucosa in the region of 14,15 and 16.

The radiological examination revealed a bone resoption in the papillar region in front of the 14-15-16 (Figure 2). 


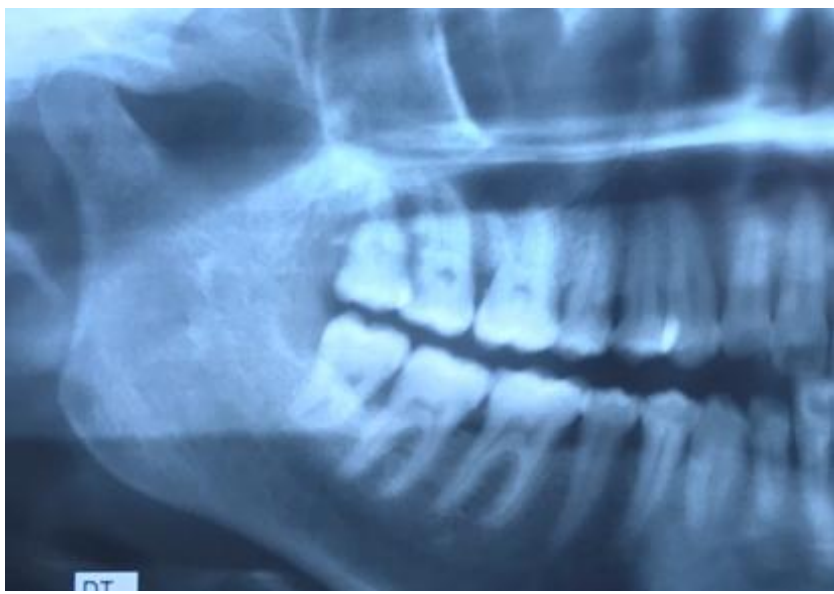

Fig. 2: Bone resorption in front of the papillar region between 14-15-16.

Based on the clinical and radiological data, the provisional diagnosis made was focal fibrous hyperplasia. Differential diagnosis was given, and has included the following chronic fibrous epulis,osteosarcoma and pyogenic granuloma. An exicional biopsy was performed. Under local anaesthesia, excisional biopsy was performed, followed by a surgical flap raised to complete the exicional mass biopsy (Figure 3) and then, analysed under microscope.

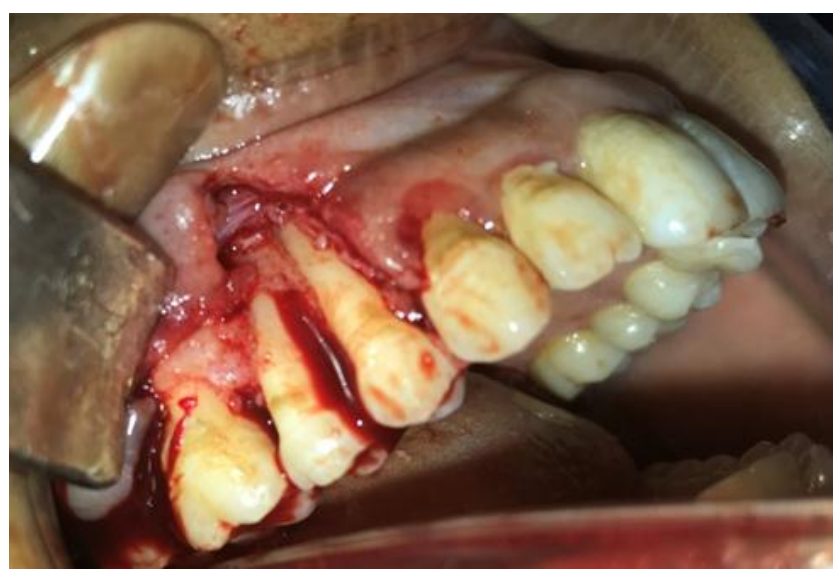

Fig. 3: Per-operative view: Surgical flap raised to complete the exicional mass biopsy.

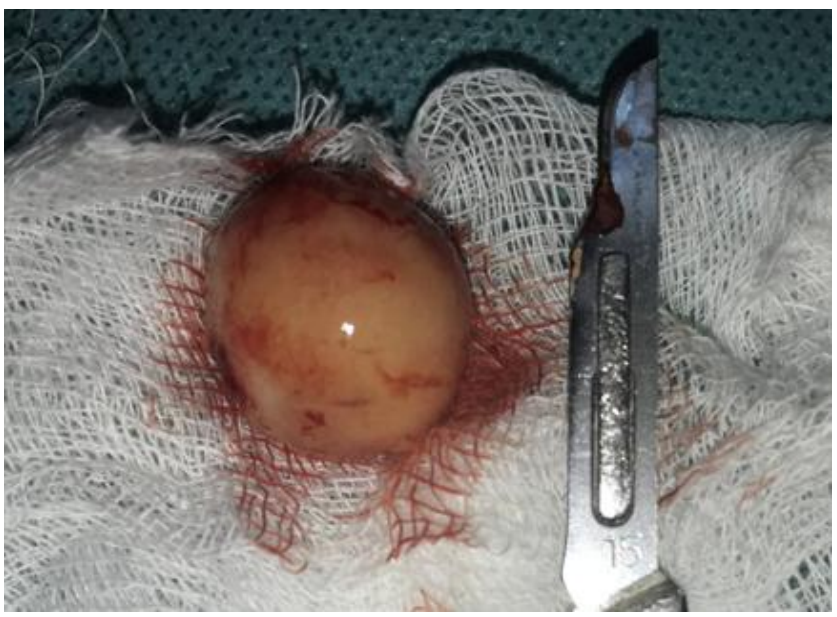

Fig. 4: The excised lesion specimen

Different sizes of multiple foci of same calcified areas within connective tissue has been revealed. Thus, the histological examination concluded a focal fibrous hyperplasia as final diagnosis for the lesion. The patient was followed-up during a period of 15 days and showed a complete healing with no sign of recurrence (Figure 5).

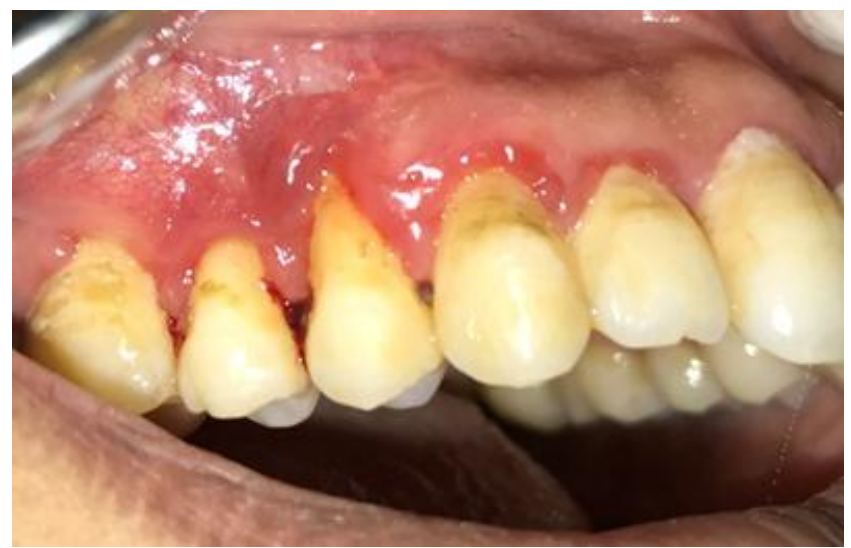

Fig 5: Follow-up after 15 days: complete healing with no sign of Recurrence.

\section{Case Report 2}

A 44 year-old female patient reported to the Oral Surgery Department of the Consultation Center of Dental Treatment with the chief complaint of bleeding from gums in manibular posterior molar region from past 6 months. No relevant medical history was reported. The lesion was gradually increased in size and no history of bleeding and pain were noted.

The Intra-oral examination revealed a sessile mass, firm in consistency and well defined in relation to 44,45 on the buccal side, measuring approximately $2.5 \times 2 \mathrm{~cm}$ in diameter, extending from distal surface of 43 to mesial surface of 47 (Figure 6).
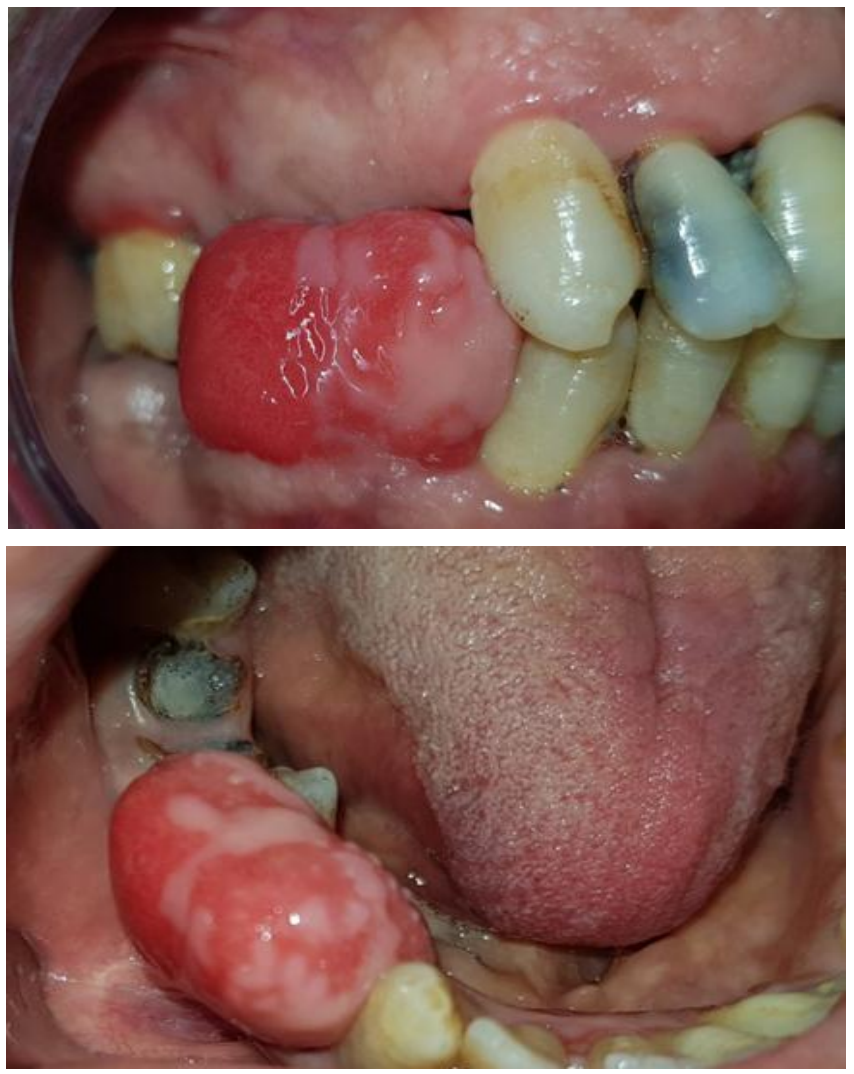

Fig. 6: Pre-operative View: Sessil mass located in the buccal gum mucosa in the region of 44,45 and 46. 
Based on the clinical symptoms, the provisional diagnosis made was focal fibrous hyperplasia. Differential diagnosis was given, and has included the following chronic fibrous epulis, osteosarcoma and pyogenic granuloma.

An exicional biopsy was performed. Under local anaesthesia, excisional biopsy was performed, followed by a surgical flap raised to complete the exicional mass biopsy (Figure 7, 8 and 9).

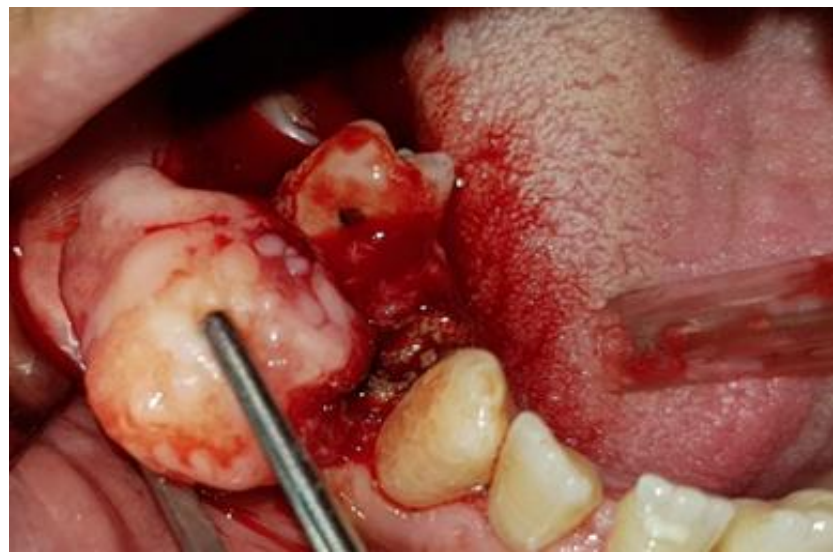

Fig. 7: Per-operative view showing the sessil aspect of the lesion.

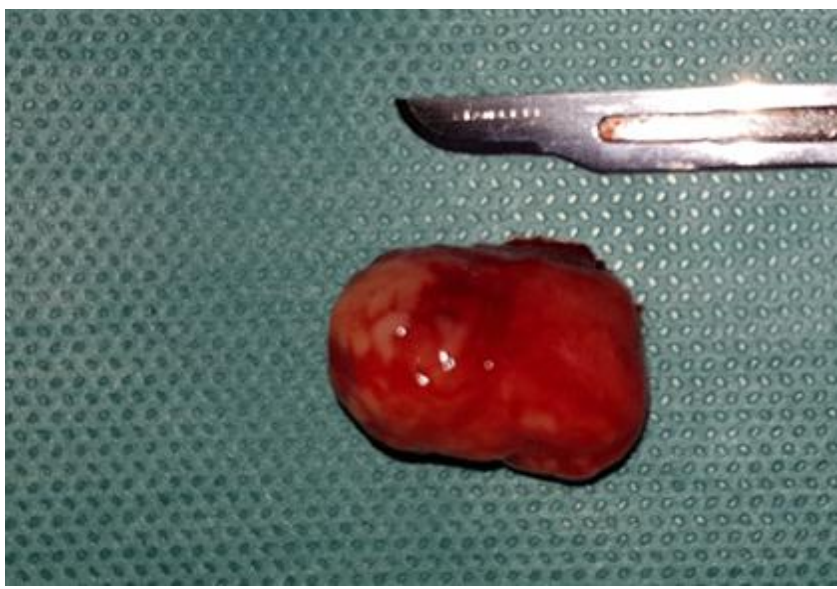

Fig. 8: The excised lesion specimen

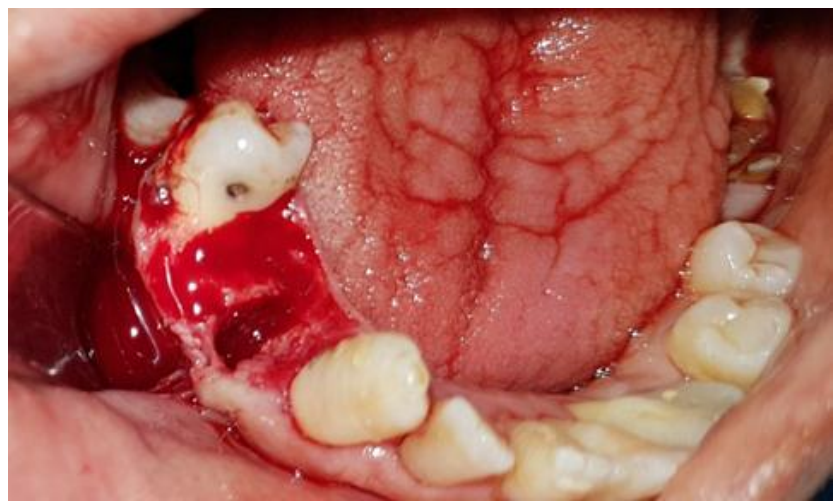

Fig. 9: Per-operative view: Surgical flap raised to complete the exicional mass biopsy in order to avoid recurrence.

The lesion specimen was then sent to pathology which revealed a mass of fibrous connective tissue nodules covered by a multilevel squamous epithelium. This lesion has no capsule, fibrous connective tissue is mixed around the connective tissue. Collagen fibers are arranged circularly (Figure 10). Thus, the histological examination concluded an focal fibrous hyperplasia as final diagnosis for the lesion. The patient has disappeared ever since, and we couldn't get in touch with him for a further follow-up.

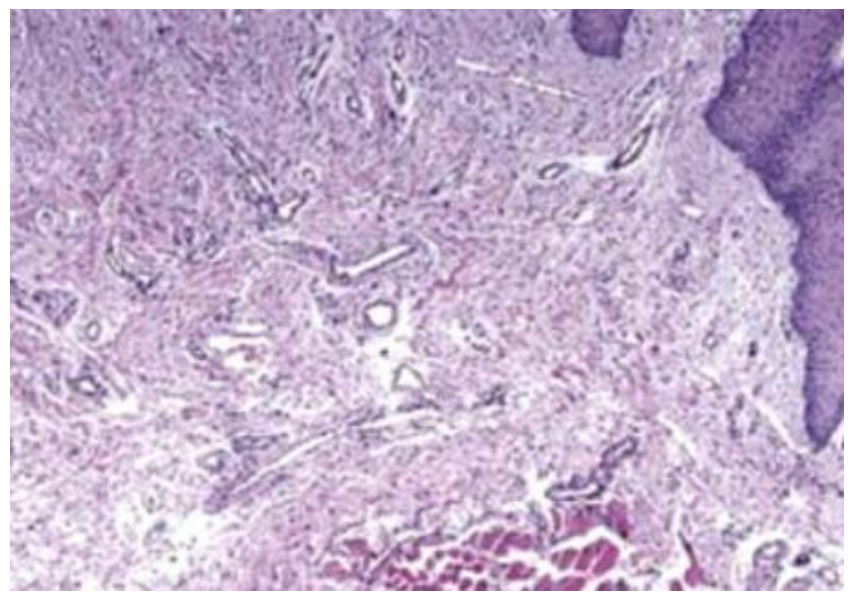

Fig. 10: Histological picture

\section{Discussion}

The term "inflammatory hyperplasia" is used to describe a large range of commonly occurring nodular growths of the oral mucosa that histologically represent inflamed fibrous and granulation tissue [5]. Epulis is often referred to a similar lesion on the gingival mucosa and size of these masses (hyperplastic) may be smaller or larger, which depends on components of inflammatory reaction and the response of healing are overemphasized in these particular lesions ${ }^{[1,6]}$.

Focal fibrous hyperplasia is also known as irritational fibroma, oral fibroma or as fibromatosis fibroma. It is connective tumor and is the most common benign soft tissue neoplasm occurring in the oral cavity. Most fibromas represent reactive focal fibrous hyperplasia due to trauma or local irritation.

The focal fibrous hyperplasia FFH affects people of all ages and both genders, but has a high frequency in female adults, as in our 2 case reports we are presenting a case of 40 -year-old female. This predilection for adults is probably related to the specific features in this range of life, which include wear dentures, lower-lip-biting habit, chronic cheek-biting and biting objects. the mechanical trauma is closely related to the development of the FFH, contrary to the idea that this lesion is a true neoplasm. In addition, it is possible that female hormones contribute to an increased production and accumulation of collagen by fibroblasts in the presence of a chronic injury. Interestingly, other reactive lesions also show a great predilection for females and are detected in the first five decades of life, when hormonal changes are most predominant ${ }^{[7,8,9,10]}$.

The frequency of focal fibrous hyperplasia is found to be more in maxilla than the mandible and more often in incisor cuspid region, ranging between $55-62 \%{ }^{[11]}$. In our first case, the lesion was present in relation to 14,15 and 16 tooth region, and between 44, 45 and 46 in the second case. The diameter of these lesions usually measures less than $1.5 \mathrm{~cm}$ and more than $3 \mathrm{~cm}$ in rare cases. As observed in the second case, a fibroma may occur at any oral cavity, most commonly seen on buccal mucosa along the plane of occlusion.

Definitive diagnosis is based on histological analysis to rule out the possibility of lesions that may have a similar appearance, such as, pyogenic granuloma (PG), peripheral giantcell granuloma (PGCG) and peripheral ossifying fibroma (POF).

Histologically they are characterized by a focal sub epithelial mass of fibrous connective tissue composed of inter 
lacing or parallel bundles of collagen, containing occasional vascular channel and variable inflammatory infiltrate. The fibroblast are apically narrow and elongated and relatively few in number. Recurrences of this lesion are uncommon or rare ${ }^{[12]}$.

In addition, it is important to explain that FFH should be differentiated from an unusual non-neoplastic lesion of the oral cavity known as giant-cell fibroma (GCF). This lesion occurs most commonly on the tongue and gingiva, in the young patients, without sex predilection. Microscopically, CFG is composed of a non-inflammated fibrous connective tissue, with the presence of large stellate cells, usually with one or two nuclei, just beneath the epithelium. Multinucleated giant cells are seen occasionally. However, the giant cells are not exclusive of the CFG and can also be seen in other lesions, including FFH, looking to be part of the normal spectrum of tissue responses to injuries [13]. Immunohistochemical stains show that these cells are only vimentin-positive, suggesting a fibroblast phenotype ${ }^{[14,15]}$.

The lesion is treated by complete local excision and removal of chronic irritant. However cook in his review reported 3 cases recurrences out of 78 biopsy specimens ${ }^{[16]}$.

\section{Conclusion}

The focal fibrous hyperplasia is a very frequent type of benign connective tumor, usually easy to diagnose. There is no reported malignant evolution and the excision is generally easy to perform.

Long term follow up is required to prevent recurrence of the lesion.

\section{Data Availability}

Not applicable

\section{Disclosure Statement}

The authors declare no conflict of interest.

\section{Funding Sources}

The authors received no financial support for the research, authorship, and/or publication of this article.

\section{Acknowledgements}

The authors thank David B. Geffen, MD for his critical review of the manuscript.

\section{Statement of Ethics}

The authors have no ethical conflicts to disclose.

\section{References}

[1] Mathur LK, Bhalodi AP, Manohar B, Bhatia A, Rai N, Mathur A. Focal fibrous hyperplasia: a case report. International Journal of Dental Clinics. 2010;2(4):56-57

[2] Kfir Y, Buchner A, Hansen L. Reactive lesions of the gingiva. A clinicopathological study of 741 cases. J Periodontol 1980;51(11):655-6.

[3] Kolte A, Kolte R, Shrirao T. Focal fibrous overgrowths: A case series and review of literature. Contemp Clin Dent 2010;1(4):271-4.

[4] Goravalingappa JP. \& Mariyappa KC. Fibroma of tonsil. Indian Journal of Otolaryngology and Head and Neck Surgery. 1999, 51:72-73

[5] Lalit K, Anand P. Balaji M.Focal fibrous hyperplasia: A Case Report.International Journal Of Dental Clinics 2010:2(4):56-57

[6] Macleod R, Soames J. Epulides: a clinicopathological study of a series of 200 consecutive lesions. British dental journal. 1987, 163(2):51-53

[7] Whitaker SB, Bouquot JE. Identification and semiquantification of estrogen and progesterone receptors in peripheral giant cell lesions of the jaws. J Periodontol. 1994;65:280-3.

[8] Saravana GHL. Oral pyogenic granuloma: A review of 137 cases. Br J Oral Maxillofac Surg. 2009;47:318-9.

[9] Mishra MB, Bhishen KA, Mishra S. Peripheral ossifying fibroma. J Oral Maxillofac Pathol. 2011;15:65-8.

[10] Katsikeris N, Kakarantza-Angelopoulou E, Angelopoulos AP. Peripheral giant cell granuloma. Clinicopathologic study of 224 new cases and review of 956 reported cases. Int J Oral Maxillofac Surg. 1988;17:94-9.

[11] Akerzoul N, Chbicheb S. Focal Fibrous Hyperplasia: Two Case Reports American Journal of Oral and Maxillofacial Surgery 2018, 5:1-7

[12] Zain RB, Fei YJ. Fibrous lesions of the gingiva: a histopathologic analysis of 204 cases. Oral surg, oral med, oral pathol 1990;70(4):466-70.

[13] de Santana Santos T, Martins-Filho PR, Piva MR, de Souza Andrade ES. Focal fibrous hyperplasia: A review of 193 cases. J Oral Maxillofac Pathol. 2014;18(Suppl 1):S86-S89.

[14] Magnusson BC, Rasmusson LG. The giant cell fibroma. A review of 103 cases with immunohistochemical findings. Acta Odontol Scand. 1995;53:293

[15] Campos E, Gomez RS. Immunocytochemical study of giant cell fibroma. Braz Dent J. 1999;10:89-92.

[16] Cooke B.E.D. The fibrous epulis \& the fibro epithelial polyp: Their histogenesis \& natural history". Br Dent J 1952;93:305-9. 